\title{
Apresentação Incomum de Vasculite Associada à Infecção por Vírus C da Hepatite
}

\section{Uncommon Presentation of Vasculitis Associated to Infection with Hepatitis C Virus}

\author{
Leopoldo Luiz dos Santos-Neto ${ }^{(1)}$, Elvis Henrique Santos Andrade(2), \\ Carlos Hirokatsu Watanabe-Silva ${ }^{(2)}$, Patrícia Eiko Yamakawa ${ }^{(2)}$
}

\section{RESUMO}

A vasculite é uma síndrome pleomórfica composta por um grupo heterogêneo de processos inflamatórios que acometem principalmente a parede dos vasos sangüíneos. A infecção pelo vírus $\mathrm{C}$ da hepatite $(\mathrm{VCH})$ pode associar-se a manifestações extra-hepáticas, incluindo doenças auto-imunes. Duas formas de vasculite podem associar-se ao VCH: a crioglobulinemia mista e a semelhante à poliarterite nodosa. O diagnóstico e o manuseio terapêutico nessas condições são desafios. Existem poucos dados a respeito da eficácia da terapia antiviral em pacientes com VCH crônica e doenças autoimunes. Apresentamos um relato de caso de vasculite de pequenos vasos de apresentação incomum associado ao $\mathrm{VCH}$.

Palavras-chave: crioglobulinemia, poliarterite nodosa, vasculite, vírus da hepatite $\mathrm{C}$.

\section{INTRODUÇÃO}

A vasculite é uma síndrome inflamatória pleomórfica que acomete principalmente a parede dos vasos sangüíneos. A infecção pelo vírus $\mathrm{C}$ da hepatite $(\mathrm{VCH})$ pode associar-se a manifestações extra-hepáticas, incluindo doenças autoimunes $^{(1,2)}$. Duas formas principais de vasculite podem associar-se ao $\mathrm{VCH}$ : a forma com crioglobulinemia mista $(\mathrm{CM})$, que envolve pequenos vasos, e aquela semelhante à poliarterite nodosa (tipo PAN), que afeta vasos de médio calibre $^{(1,2,3)}$. A diferenciação entre ambas é dificultada pelas superposições de manifestações clínicas, incluindo neuropatia periférica, artralgia, mialgia, comprometimento renal e infiltrado vascular inflamatório ${ }^{(3)}$.

\begin{abstract}
Vasculitis is a pleomorfic inflammatory syndrome that involves mainly the wall of blood vessels. The hepatitis $C$ virus infection may be associated to extra-hepatic manifestations, including autoimmune diseases. Two forms of vasculitis have been associated to hepatitis $C$ virus, namely: mixed cryoglobulinemia and polyarteritis nodosa. The diagnosis and the therapeutic management of these conditions are clinical challenges. There are few data available in the literature about the antiviral treatment efficacy in patients with hepatitis $C$ virus and autoimmune diseases. We describe an unusual patient displaying vasculitis of small vessels and with hepatitis $C$ virus infection.
\end{abstract}

Keywords: cryoglobulimemia, polyarteritis nodosa, vasculitis, hepatitis $C$ virus.

O diagnóstico e o manuseio terapêutico da associação de vasculite e VCH são desafios para o clínico. Existem poucos estudos sobre a eficácia e a segurança com relação ao uso de terapia antiviral em pacientes com VCH crônica e doenças auto-imunes. Apresentamos um relato de caso de vasculite de pequenos vasos de apresentação incomum associada ao VCH e uma breve revisão de literatura.

\section{RELATO DE CASO}

Em julho de 2000, homem de 47 anos apresentou crise hipertensiva $-240 \mathrm{mmHg}$ x $100 \mathrm{mmHg}$, emagrecimento $24 \mathrm{~kg}$ em 4 meses -, mialgia difusa, parestesia palmo-plantar e lesões cutâneas eritêmato-papulares em extremidades.

Recebido em 13/4/2007. Aprovado, após revisão, em 9/9/2007. Declaramos a inexistência de conflitos de interesse

Hospital Universitário de Brasília (HUB), Universidade de Brasília.

1. MD, PhD, FACP, professor-associado de Medicina Interna.

2. Estudantes de Medicina da Universidade de Brasília (UnB)

Endereço para correspondência: Leopoldo Luiz dos Santos-Neto, Hospital Universitário de Brasília (HUB), Centro de Clínica Médica Vanize Macedo, Universidade de Brasília, CEP 70919-970, Caixa Postal: 04438,Brasília, DF, e-mail: leoneto@uninet.com.br 
O paciente não apresentava xeroftalmia ou xerostomia. $\mathrm{Na}$ ocasião, foi identificada lesão renal: creatinina sérica de $4,9 \mathrm{mg} / \mathrm{dL}$; depuração de creatinina de $5 \mathrm{~mL} / \mathrm{min} / 1,73 \mathrm{~m}^{2}$; e proteinúria de $175 \mathrm{mg} / 24 \mathrm{~h}$. Indicou-se, então, hemodiálise e nifedipina de ação prolongada, $60 \mathrm{mg} / \mathrm{dia}$, para controle da hipertensão arterial.

Investigação laboratorial subseqüente mostrou ANCA, Anti-Sm, Anti-DNA e FAN negativos. O fator reumatóide foi positivo, C3 de $87 \mathrm{mg} / \mathrm{dL}$; C4 de $13 \mathrm{mg} / \mathrm{dL}$ e CH50 de $46 \mathrm{U} / \mathrm{mL}$. Os quatro testes realizados para crioglobulinas foram negativos (ponto de corte $35 \mu \mathrm{g} / \mathrm{mL}$ ). A radiografia de tórax e a tomografia de abdômen foram normais. A sorologia para $\mathrm{VCH}$ foi positiva e a carga viral foi de 500.000 cópias $/ \mathrm{mL}$ (PCR - tempo real). A sorologia para vírus B da hepatite foi negativa.

A biópsia de pele mostrou vasculite linfocítica de pequenos vasos (arteríolas) com depósito de IgA, IgM e C3. A biópsia de músculo evidenciou infiltrado mononuclear perivascular. A biópsia hepática foi compatível com hepatopatia crônica pelo $\mathrm{VCH}$, com moderada atividade inflamatória. A biópsia renal identificou atrofia tubular e fibrose intersticial difusa, com imunofluorescência negativa para IgG, IgA, IgM, Clq e C3 e atrofia isquêmica do parênquima renal. A eletroneuromiografia revelou uma neuropatia periférica sensitivo-motora, assimétrica, predominantemente axonal. A angiotomografia realizada não identificou microaneurisma em território mesentérico e renal.

Em janeiro de 2001, iniciou-se esquema com ciclofosfamida oral, $50 \mathrm{mg}$ por dia, por um ano. Após recuperação da função renal, a ciclofosfamida foi aumentada para $75 \mathrm{mg} /$ dia por mais oito meses. Com isso, obteve-se remissão da vasculite cutânea e suspensão da diálise. Em abril de 2006, mantinha-se assintomático, com a depuração de creatinina de $58,90 \mathrm{~mL} / \mathrm{min} / 1,73 \mathrm{~m}^{2}$ e creatinina sérica de $1,8 \mathrm{mg} / \mathrm{dL}$. Faz uso de anlodipino/enalapril, $10 \mathrm{mg} / 40 \mathrm{mg} / \mathrm{dia}$, rilmenidina, $2 \mathrm{mg} /$ dia, clonidina $0,2 \mathrm{mg} /$ dia, e furosemida, $40 \mathrm{mg} / \mathrm{dia}$. A carga viral de HCV foi de $13.544 .001 \mathrm{UI} / \mathrm{mL}$; TGO 81 U/L, TGP 113 U/L, gama-GT 139 U/L. Em março de 2006, a nova biópsia hepática realizada foi semelhante à anterior - padrão portal em atividade, sem fibrose. Foi indicada a utilização de ribavirina e peg-interferon, porém o paciente recusou o tratamento.

\section{DISCUSSÃO}

A infecção pelo VCH é uma doença que afeta cerca de 170 milhões de pessoas no mundo ${ }^{(3)}$, caracterizando-se principalmente por apresentar um curso indolente e poden- do evoluir para comprometimento hepático de moderado a grave. No entanto, a infecção pelo $\mathrm{VCH}$ pode cursar com manifestações extra-hepáticas que contribuem para a maior morbidade da doença. Destacam-se as manifestações reumatológicas que incluem artralgia, mialgia, síndrome de Sjögren e vasculites, como a crioglobulinemia mista e a poliarterite nodosa.

Há vários relatos de associação entre PAN e doenças infecciosas, incluindo o vírus da hepatite $\mathrm{B}$, o vírus da hepatite $\mathrm{C}$, o vírus da imunodeficiência humana, o parvovírus B19 e o Chlamydia trachomatis ${ }^{(2,3)}$. A produção de imunocomplexos parece ter um papel-chave na patogênese da PAN e poderia justificar a associação dessa afecção a agentes infecciosos de natureza tão variável ${ }^{(3)}$. O paciente em questão apresentou infecção assintomática pelo $\mathrm{VCH}$ não-tratada, que teve como manifestação clínica inicial um quadro semelhante à PAN.

O caso apresentado preenche os critérios da Academia Norte-Americana de Reumatologia para Poliarterite Nodosa $^{(4)}$ : o paciente apresentou perda ponderal de $24 \mathrm{~kg}$, polineuropatia periférica, hipertensão arterial com pressão diastólica de $100 \mathrm{mmHg}$, insuficiência renal com proteinúria discreta. Entretanto, apesar de o quadro clínico indicar PAN, há algumas considerações a serem feitas.

Segundo o Consenso de Chapel Hill ${ }^{(5,6)}$, PAN se caracteriza por inflamação necrotizante de artérias de pequeno a médio calibre, com acometimento característico de artérias renais e viscerais, sem acometer vasos de menor calibre como arteríolas, capilares e vênulas. Na histopatologia de pele foi identificado depósito de imunoglobulinas (IgA, IgM) e complemento C3 em arteríolas, mas esse achado não é descrito na PAN. Não foram identificados outros achados mais específicos de PAN como vasculite em vasos de médio calibre ou presença de aneurismas na tomografia computadorizada de abdômen.

Polineuropatia assimétrica sensitiva, vasculite cutânea acometendo arteríolas, com depósito de complexos imunes e complemento, fator reumatóide positivo e evidência de consumo de complemento são mais sugestivos de CM, porém podem ser também identificados em pacientes com $\operatorname{PAN}^{(1,6,7,8,9)}$. No estudo de Cacoub et al ${ }^{(1)}$, o fator reumatóide foi identificado em sete dos dez pacientes com vasculite tipo PAN e em cinco dos sete com CM. O consumo de complemento foi identificado em $80 \%$ dos pacientes com vasculite tipo PAN e, nos pacientes com crioglobulinemia, chegou a $100 \%$. No caso aqui relatado, a presença de fator reumatóide e o consumo de complementos sugerem o quadro de CM. 
Por outro lado, a apresentação clínica com hipertensão e insuficiência renal com descrição histológica sugestiva de isquemia renal, sem glomerulonefrite, sem depósito glomerular de imunoglobulinas ou de complemento é compatível com $\mathrm{PAN}^{(3)}$. Na CM associada ao $\mathrm{VCH}$, a forma clínica e histopatológica mais vista é a glomerulonefrite membranoproliferativa tipo I, representando $70 \%$ a $80 \%$ das lesões renais relacionadas à vasculite crioglobulinêmica ${ }^{(1,3)}$.

Em relação à crioglobulinemia, pode-se dizer que é um achado comum e esperado em pacientes com infecção crônica pelo $\mathrm{VCH}$, bem como em colagenoses (lúpus, síndrome de Sjögren), em outras infecções (hepatite B) e nos casos de PAN “clássico”, associado ou não ao $\mathrm{VCH}^{(1)}$. Sua presença não determina necessariamente uma síndrome vasculítica, mesmo no contexto de PAN ou $\mathrm{CM}^{(1)}$. Além disso, a pesquisa de crioglobulinemia negativa não exclui o diagnóstico de vasculite por CM, já que a detecção depende de técnica e cuidados especiais, relacionados às mudanças conformacionais e na ligação das crioglobulinas que acontecem com a mudança de temperatura e $\mathrm{pH}$, por exemplo $^{(1,7,8)}$.

No estudo de Cacoub et al..$^{(1)}$, o grupo com vasculite do tipo PAN teve apresentação mais grave do que aqueles com CM; $50 \%$ dos casos iniciaram com hipertensão arterial e insuficiência renal. A biópsia renal foi realizada apenas em um paciente, que também evoluiu para diálise em poucas semanas. A biópsia muscular do caso aqui relatado - infiltrado predominantemente mononuclear em pequenos vasos - também é semelhante a dois casos descritos no grupo do tipo $\mathrm{PAN}^{(1)}$.

Nosso caso apresenta mais semelhanças clínicas e histopatológicas com os pacientes com CM estudados por Cacoub et al. ${ }^{(1)}$ do que com os do grupo PAN. Naquele trabalho, os pacientes do grupo PAN abriram o quadro com sintomatologia mais grave, como hipertensão maligna e vasculite cerebral. No entanto, os pacientes do grupo CM não preenchiam os critérios para poliarterite nodosa, eram portadores há mais tempo de VCH e com lesão hepática mais grave ${ }^{(1)}$. O caso aqui apresentado não é típico de PAN nem de CM. Poderíamos, portanto, especular a coexistência das duas condições clínicas - vasculite crioglobulinêmica e PAN - como manifestações extra-hepáticas do VCH ocorrendo simultaneamente no caso do paciente apresentado.

A classificação precisa de uma síndrome vasculítica nem sempre é possível, dadas as semelhanças clínicas, bioquímicas e histológicas dos diversos tipos ${ }^{(6)}$. A indefinição diagnóstica, no entanto, não deve adiar o início do tratamento. A terapêutica de vasculites primárias inclui essencialmente o uso de corticosteróides e imunossupressores, como a ciclofosfamida $^{(1,2,3)}$. Já o manejo de vasculites secundárias a infecções virais inclui a abordagem etiológica no tratamento, como o uso de ribavirina e interferon-alfa ${ }^{(1,2,3)}$. Os dados disponíveis na literatura não permitem estabelecer a melhor terapêutica para vasculites associadas ao $\mathrm{VCH}$.

O IFN, em virtude de seu efeito antiangiogênico, pode acentuar uma isquemia preexistente, causando ulcerações na pele, neuropatia isquêmica, além de dificultar a melhora de áreas previamente isquêmicas ${ }^{(9)}$. Assim, é descrito que pode haver exacerbação de um quadro de vasculite preexistente em pacientes com VCH em tratamento com IFN ${ }^{(9)}$. Beuthien et al. ${ }^{(9)}$ citam quatro relatos de vasculite da forma tipo PAN, sem crioglobulinas detectáveis, confirmados histologicamente como secundários ao uso de interferon.

Além do interferon, o uso de imunossupressores e de plasmaférese pode ser tentado nas formas graves de vasculite associada ao $\mathrm{VCH}$ do tipo $\mathrm{PAN}^{(1,2,3,9)}$. Imunossupressores são opções para o tratamento de vasculites associadas ao VCH caso não haja resposta à associação IFN e ribavirina ou se este tratamento provocar efeitos colaterais ${ }^{(9)}$. O inconveniente dos imunossupressores é que seu uso isolado pode provocar aumento da viremia, com reativação da lesão hepática $^{(1,2,3,9)}$. Nosso caso apresentou boa resposta à ciclofosfamida, porém com aumento significativo da viremia.

Em resumo, o tratamento do vírus pode diminuir as manifestações hepáticas e extra-hepáticas do $\mathrm{VCH}$, porém pode causar exacerbação da vasculite $e^{(1,2,3,8,9)}$. Por outro lado, o tratamento da vasculite com imunossupressor pode piorar a carga viral, provocando piora de manifestações hepáticas $^{(1,2,3,9)}$, mesmo com a melhora da vasculite ${ }^{(9)}$. O controle da viremia, portanto, ainda constitui um desafio.

\section{CONCLUSÃO}

A apresentação de vasculite associada ao vírus $\mathrm{C}$ da hepatite é uma condição de difícil diagnóstico e manejo clínico, pois não existem critérios que permitam uma classificação adequada, e o uso de medicação imunossupressora tem como efeito adverso conhecido o aumento da carga viral do $\mathrm{VCH}$, podendo ocorrer recrudescimento da vasculite. Esse provavelmente é o primeiro caso da literatura de vasculite associada ao $\mathrm{VCH}$ com características tanto de PAN quanto de CM, com lesão renal estabelecida, que apresentou boa resposta ao tratamento imunossupressor com ciclofosfamida, embora à custa de um grande aumento da carga viral do vírus $\mathrm{C}$ da hepatite. 


\section{REFERÊNCIAS}

1. Cacoub P, Maisonobe T, Thibault V, et al.: Systemic vasculitis in patients with hepatitis C. J Rheumatol 28(1): 109-18, 2001.

2. Ramos-Casals M, Trejo O, Garcia-Carrasco M, Font J: Therapeutic management of extrahepatic manifestations in patients with chronic hepatitis $\mathrm{C}$ virus infection. Rheumatology 42(7): 818-28, 2003.

3. Sene D, Limal N Cacoub P: Hepatitis C Virus-Associated Extrahepatic Manifestations: A Review. Metabolic Brain Disease 19(3/4), 2004.

4. Lightfoot RW Jr, Michel BA, Bloch DA, et al.: The American College of Rheumatology 1990 criteria for the classification of polyarteritis nodosa. Arthritis Rheum 33(8): 1088-93, 1990.
5. Jennette JC, Falk RJ, Andrassy K, et al.: Nomenclature of systemic vasculitides: the proposal of an international consensus conference. Arthritis Rheum 37: 187-92, 1994.

6. Davies D J: Small vessel vasculitis. Cardiovasc Pathol 14: 335-46, 2005.

7. Sansonno, D, Dammacco F: Hepatitis C virus, cryoglobulinaemia, and vasculitis: immune complex relations. Lancet Infect Dis 5: 227-36, 2005.

8. Morra E: Cryoglobulinemia. Hematology 1: 368-72, 2005.

9. Beuthien W, Mellinghoff HU, Kempis J: Vasculitic complications of interferon-alpha treatment for chronic hepatitis $\mathrm{C}$ virus infection: case report and review of the literature. Clin Rheumatol 24(5): 507-15, 2005. 